\section{البصيرة: مجلة الداراسات الإسلامية \\ AL-BASHIRAH: JOURNAL OF ISLAMIC STUIDES \\ Vol. 1 No. 1(2020): 61-80}

Website: https://journal.stiba.ac.id

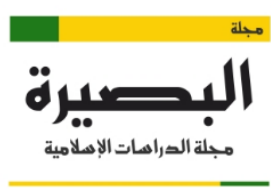

AL-BASHIRAH

\title{
المذذب الشافعي في إندونيسيا؛ تأريخه و آثاره
}

\author{
عحمد إحسان \\ المعهد العالي للدراسات الإسلامية والعربية بمكسر \\ البريد الإلكتروني: muhikhsan@stiba.ac.id
}

\begin{abstract}
المستخلص
هذا البحث يقصد من خلاله: معرفة مدى جذور تاريخي للمذهب الشافعي في إندونيسيا من حيث وصوله وانتشاره فيها، و يقصد أيضا معرفة

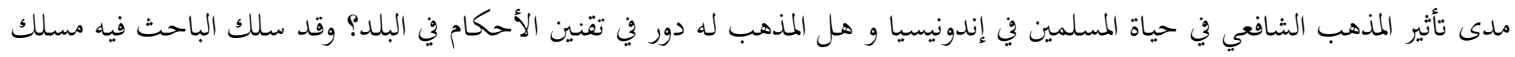

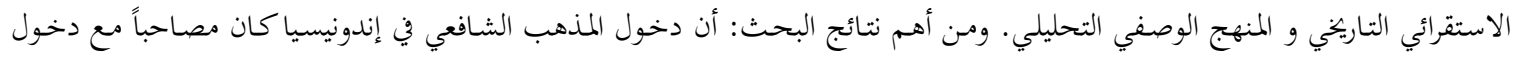

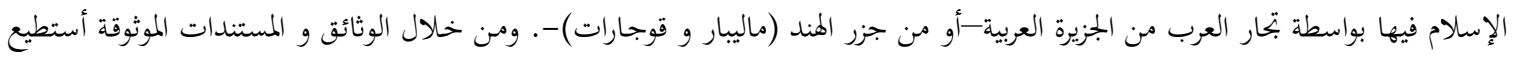

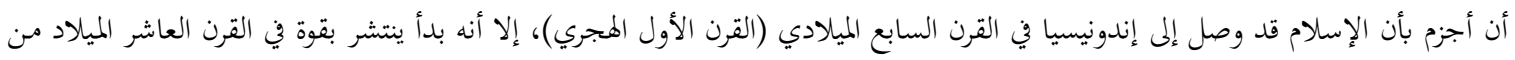

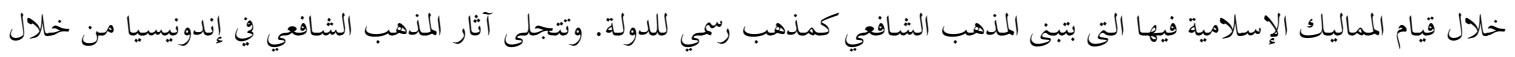

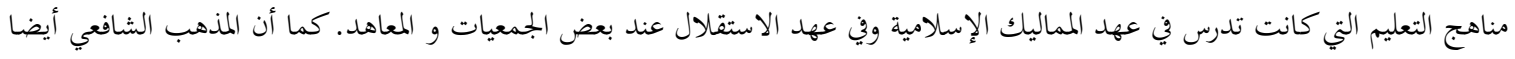

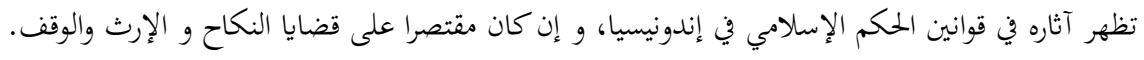

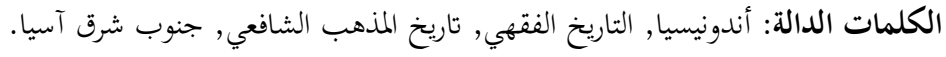

\section{The Mazhab of Shafi'i in Indonesia: Its History and Influence}

\section{Muhammd Ihsan}

Sekolah Tinggi Ilmu Islam dan Bahasa Arab (STIBA) Makassar, Indonesia

Email: muhikhsan@stiba.ac.id

\begin{abstract}
This study aims to identify the extent to which the historical roots of the Shafi'i school in Indonesia in terms of its arrival and spreading and to determine the extent of the influence of the Shafi'i school in the lives of Muslims in Indonesia and whether it plays a role in the codification of laws in Indonesia? The researcher employed the historical inductive approach and the descriptive-analytical approach. Among the results of the research are that the entry of the Shafi'i school in Indonesia was accompanied by the entry of Islam in it by Arab traders from the Arabian Peninsula - or the Indies (Malibar and Gujarat). Based on reliable documents, I can confirm that Islam entered Indonesia in the seventh century AD (first century in Hijriyah), yet began to spread strongly in the tenth century AD through the emergence of Islamic kingdoms in the archipelago which adopted the Shafi'i school as the official school of the state. The influence of the Shafi'i school is evident in Indonesia on the educational curriculum taught in the era of the Islamic kingdoms and
\end{abstract}

$$
\text { محمد إحسان, المذهب الشافعي في إندونيسيا؛ تأريخه و آثاره }
$$




\section{البصيرة: مجلة الدراسات الإسلامية \\ AL-BASHIRAH: JOURNAL OF ISLAMIC STUIDES \\ Vol. 1 No. 1(2020): 61-80}

Website: https://journal.stiba.ac.id

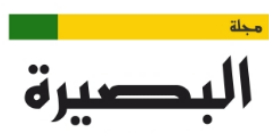

مجلة الصراهات الإهلامية

AL-BASHIRAH

the era of independence in several institutions and Islamic boarding schools. The Shafi'i school also shows its influence in the law of Islamic governance in Indonesia, although it is limited to matters of marriage, inheritance, and waqf.

Keywords: Indonesia, Southeast Asia, the history of the Shafi'i school, the history of fiqh

المقدمة

وقد تميزت الأمة المسلمة بثراء فقهي لا يوجد له نظير في سائر الديانات والمعتقدات والمجتمعات، ونبغ

فيه نوابغ قل أن يوجد لهم نظير. إن الأئمة الذين نفاخر بهم كثر ولكن اشهرهم في المجال الفقهي أربعة: أبو حنيفة ومالك والشافعي وأحمد.

لقد شكل هؤلاء الأئمة أربع مدارس فقهية، سميت بالمذاهب، واستقرت من أيام أصحابها إلى يوم الناس

والمذاهب الفقهية هي اجتهادات في فهم النصوص الشرعية قد تصيب وقد تخطيء، ولهذا فالحق ليس

محصورا في أحدها لا يخزج عنه بل الحق موزع عليها جميعا بل وعلى بقية الأئمة ممن كان لهم أتباع ثم انقرضوا كالإسحاقية أتبـاع أسحق بـن راهوية والظاهريـة أتباع داود، وغيرهم أو ممن ليس لهم أتبـاع يتبنون أفكارهم ويدافعون عنها كفقهاء المدينة السبعة وغيرهم.

هذا وقد حظيت المذاهب الأربعة بقبول واسع لدى المسلمين وجاء فترات للأمة لا تكاد بجد فيها أحدا إلا وهو ينتسب لمذهب منها، بل استحوذ كل مذاهب في غالب الأحيان على مناطق ومواضع شاسعة، فيقال مثلا بلاد كذا جميعها شافعية أو حنفية، وذلك له عدة عوامل و يكفي أن نذكر هنا أن من أهم هذه العوامل: نبوغ جماعات من العلماء الذين تبنوا نشر هذه المذاهب والتأصيل لما والإفتاء بموجبها، والاستنباط تبعا لقواعدها.

وبسبب كثرة العلماء في المدرسة الواحدة وتتابع السنين وتباعد الأقطار، نشأت مجموعة بعض القضايا

التي من خلالها يمكن أن يميز الراجح في المذهب وهو المعبر عنه بالمعتمد مـن غيره، وبين مراتب العلمـاء، واصطلاحاتم، ووضع منهج دراسي يسير عليه الطالب كي يتمكن من معرفة المذهب وغيرها.

\footnotetext{
' ' المدخل إلى مذهب الإمام الشافعي لفهد الحبيشي, ص. r. راجع أيضا: تاريخ المذهب الشافعي في فلسطين (رسالة مقدمة

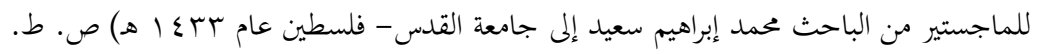
محمد إحسان, المذهب الشافعي في إندونيسيا؛ تأريخه و آثاره 
البصيرة: مجلة الاراسات الإسلامية

AL-BASHIRAH: JOURNAL OF ISLAMIC STUIDES

Vol. 1 No. 1(2020): 61-80

Website: https://journal.stiba.ac.id

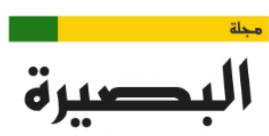

مجلة الصراهات الإهلامية

AL-BASHIRAH

هذا ومما اشتهر عن بلاد جنوب شرق أسيا و إندونيسيا على سبيل الخصوص أن أهلها قد انتحلوا

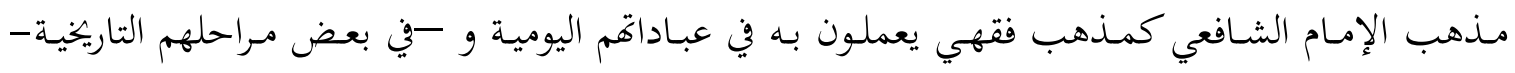

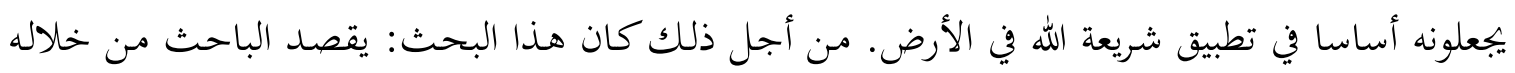

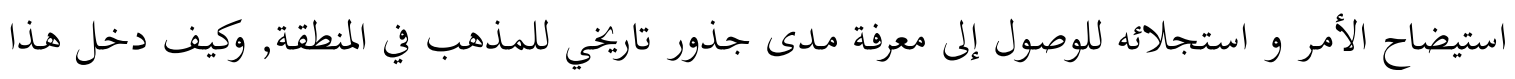

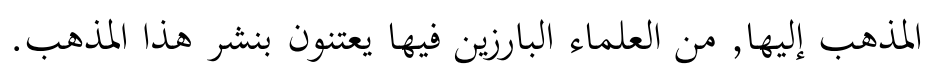
و الهدف الآخر من البحث هو معرفة مدى تأثير المذهب الشافعي في حياة المسلمين في إندونيسيا و

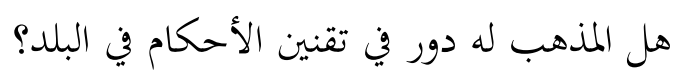

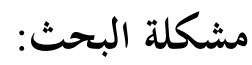

بناءً على ما تقدم فيمكن تلخيص مشكلة البحث من خلال الأسئلة التالية:

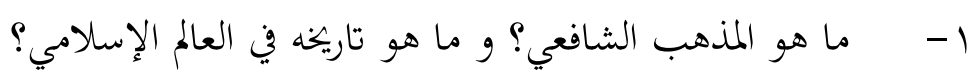

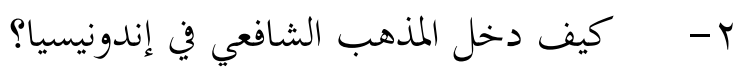

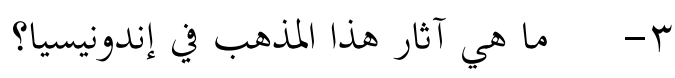

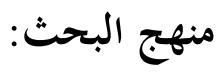

اتبعت في هذا البحث منهجين أساسيين: المنهج الاستقرائي التاريخي و المنهج الوصفي التحليلي,

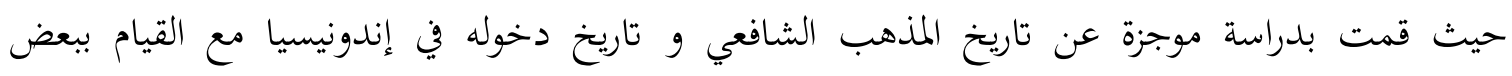

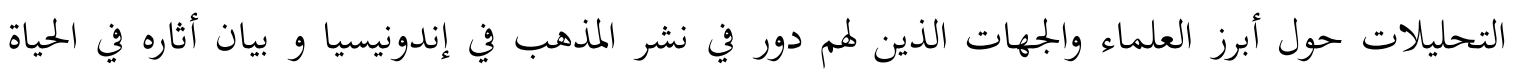
اليومية و في القوانين الإندونيسية.

المبحث الأول: المذهب الشافعي: تعريفٌ و موجزُ تاريخه في العالم الإسلامي المطلب الأول: تعريف المذهب الشافعي بدايةً لا بد لنا من بيان معنى كل كلمة ترد في تركيب "المذهب الشافعي". 
البصيرة: مجلة الاراسات الإسلامية

AL-BASHIRAH: JOURNAL OF ISLAMIC STUIDES

Vol. 1 No. 1(2020): 61-80

Website: https://journal.stiba.ac.id

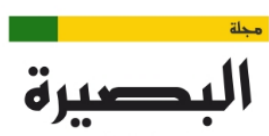

مجلة الدراهات الإهلامية

AL-BASHIRAH

فالمذهب لغة: السير و المرور , وهو مصدر بمعنى الذهاب أي الطريق. وهو عند الفقهاء عبارة عن

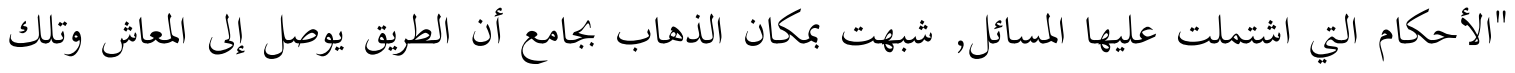

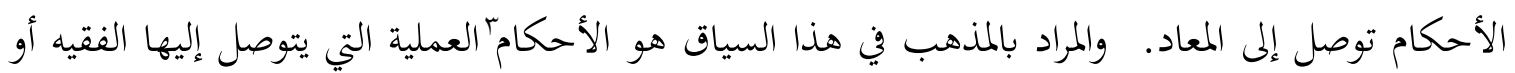
العالم و طريقته في استنباط تلك الأحكام من أدلتها.

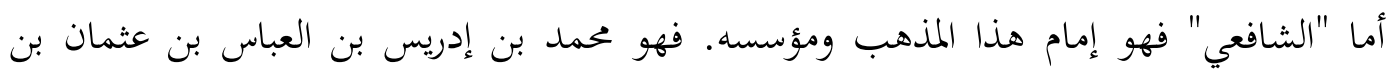

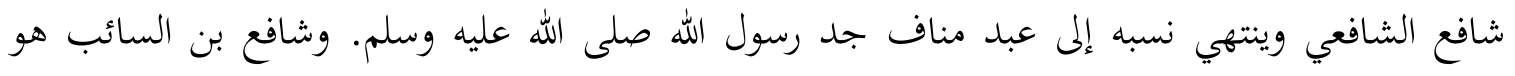
الذي ينسب إليه الشافعي. فاجتمع فيه -رحمه الله- شرف النسب من جهتين: من جهة كونه قرشيا (وهي الميزة التي يتميز بها

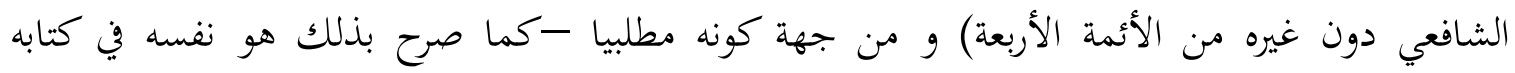

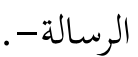

ولد رمه الله بغزة، و قيل: بعسقلان، و قيل: بمنى، و قيل باليمن سنة ـ0 اهـ -و هي السنة التي توفي

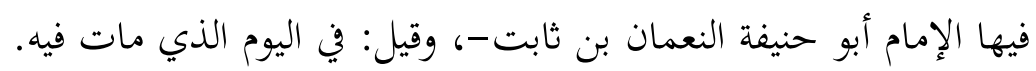

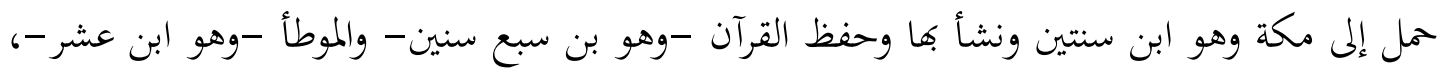

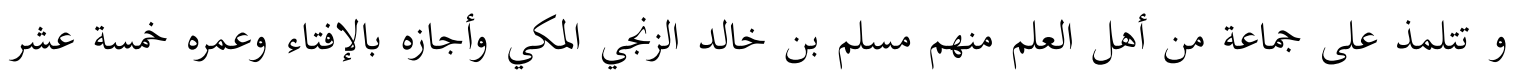

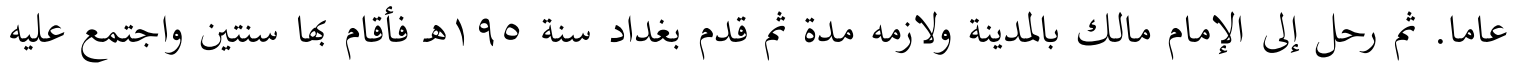

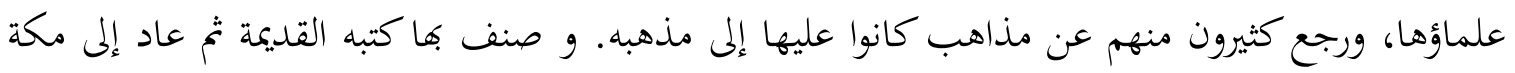

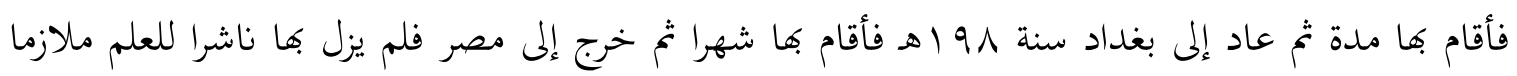

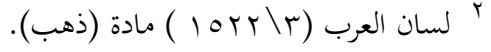

$$
\begin{aligned}
& \text { r r تحفة الحبيب على شرح الخطيب (VY) }
\end{aligned}
$$

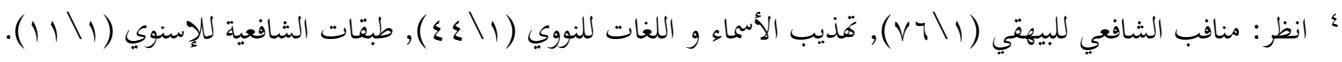

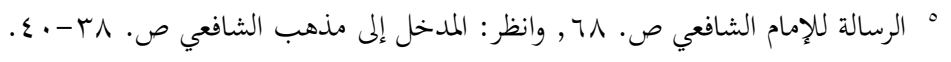

$$
\begin{aligned}
& \text { محمد إحسان,المذهب الشافعي في إندونيسيا؛ تأريخه و آثاره }
\end{aligned}
$$


البصيرة: مجلة الاراسات الإسلامية

AL-BASHIRAH: JOURNAL OF ISLAMIC STUIDES

Vol. 1 No. 1(2020): 61-80

Website: https://journal.stiba.ac.id

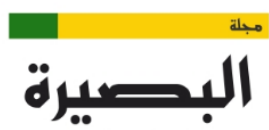

مجلة الصراعات الإهلامية

AL-BASHIRAH

للاشتغال بجامعها العتيق إلى أن أصابته ضربة شديدة فمرض بسببها أياما وقيل مات بسبب البواسير ثم انتقل إلى رحمة الله تعالى يوم الجمعة آخر رجب من عام ع ـ بهـ ودفن بالقرافة بعد العصر من يومه.

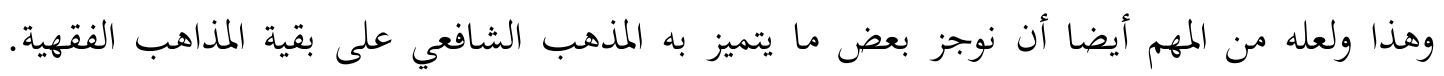

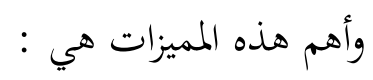

1- - جمعه بين الففه و الحديث: فهو يعتبر وسطا بين المدرستين الكبيرتين في تلك الفترة: مدرسة

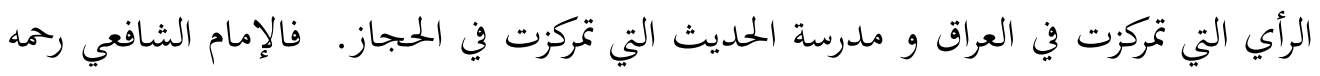
الله قد تلقى علومه من أهل الحجاز (كالإمام مالك و سفيان بن عيينة). و جلس أيضا بين يدي علماء العراق وعلى رأسهم: محمد بن الحسن -من أكبر تلاميذ أبي حنيفة رمهم الله جميعا- . فهو بهذا قد جمع بين علم أهل الأثر و أهل الرأي.

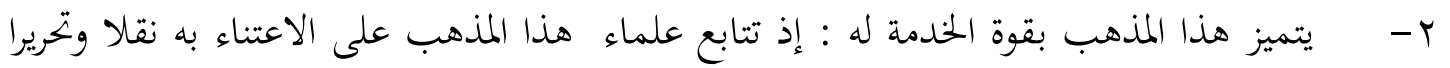

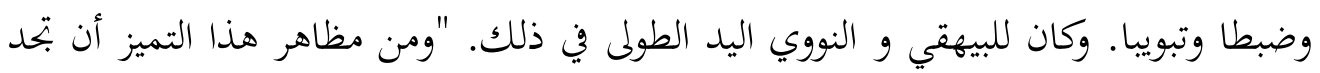

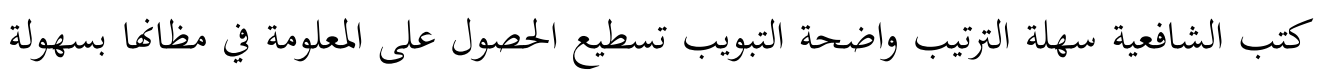

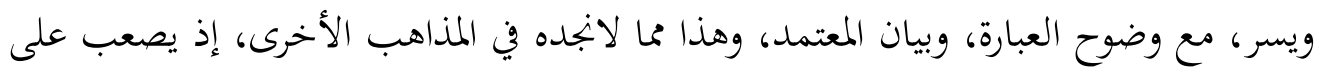

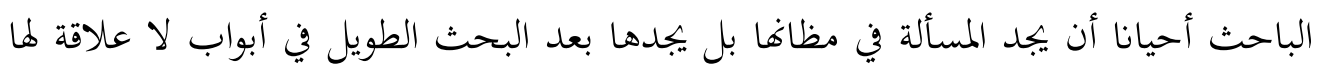

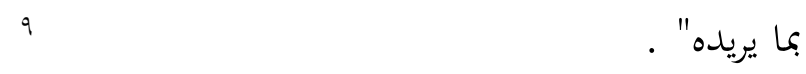

r- كثرة المجتهدين الذين تخرجوا من مدرسة المذهب الشافعي, سواء الذين صاروا من بعد بجتهدين

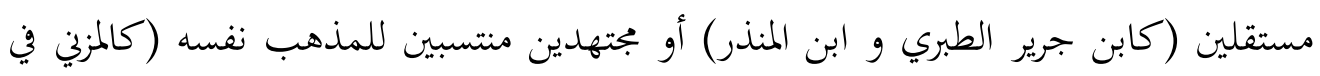

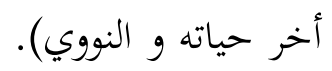

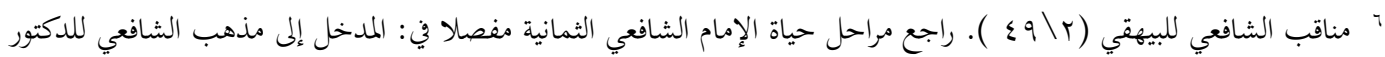

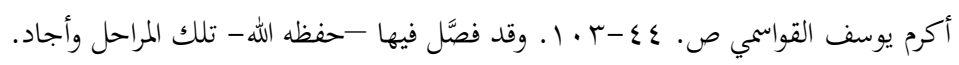

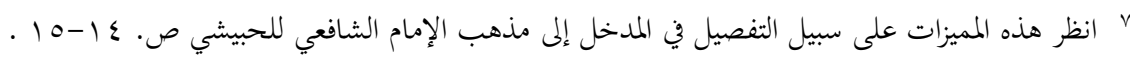

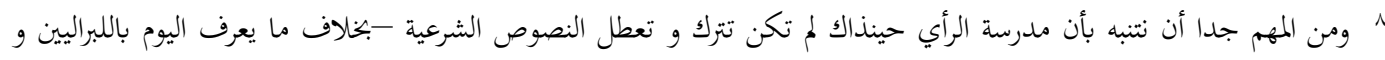

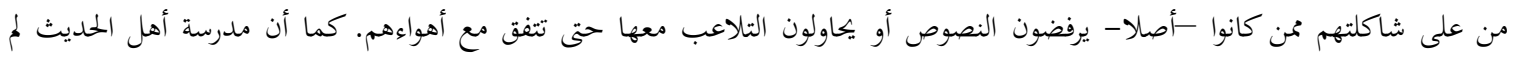
يكونوا يوما من الأيام من الأغبياء حتى -كما يقال - يعطلوا عقولمم و تفكيرهم و ذكاءهم في فهم النصوص والأدلة والواقع.

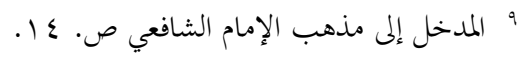

محمد إحسان, المذهب الشافعي في إندونيسيا؛ تأريخه و آثاره 
البصيرة: مجلة الاراسات الإسلامية

AL-BASHIRAH: JOURNAL OF ISLAMIC STUIDES

Vol. 1 No. 1(2020): 61-80

Website: https://journal.stiba.ac.id

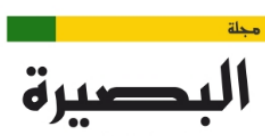

مجلة الصراهات الإهلامية

AL-BASHIRAH

JOURNAL OF ISLAMIC STUDIES

المطلب الثاني: موجز تاريخه في العالم الإسلامي

يهدف هذا المطلب إلى إيضاح مسيرة المذهب الشافعي عبر التاريخ على سبيل الإيجاز ليعطي تصورا

كيف نشأ المذهب و تطور واستقر و انتشر في أرجاء العالم الإسلامي.

وردت عدة تقسيمات لتاريخ نشأة المذهب و تطووه عند الباحثين في تاريخ المذهب الشافعي. من ون

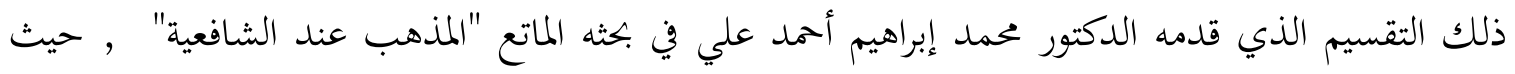

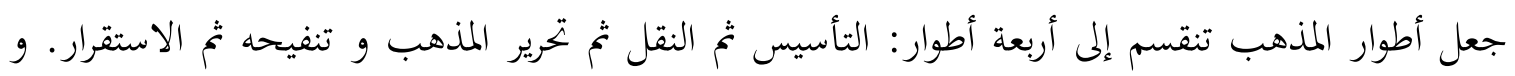
تفصيله كما يلي:

الطور الأول: طور تأسيس المذهب:

يشمل هذا الطور حياة الإمام الشافعي نفسه رحمه الله. وقد بتحلى في هذا الطور اجتهاده المطلق من

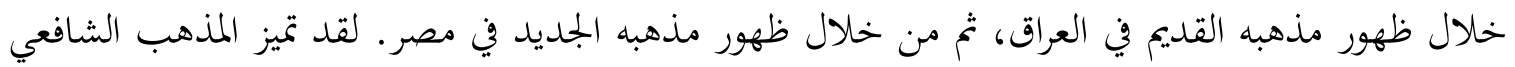

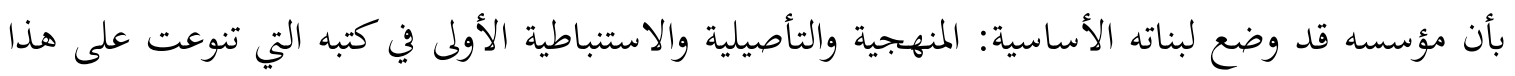

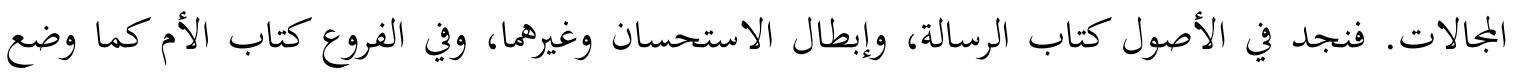
كتبا في الخلاف مثل كتاب اختلاف أبي حنيفة وابن أبي ليلى وغيره. وانتهى هذا الطور التأسيسي بوفاة الإمام رحمه الله سنة ع ب ب هـ.

الطور الثاني: طور النقل

امتد هذا الطور من وفاة الإمام الشافعي (عام ع · ب هـ) إلى أواخر القرن السادس الهجري. والمراد بهذا

الطور هو بداية مرحلة نقل فقه الإمام الشافعي وخدمته و نشره بيد تلاميذه في العراق و مصر و غيرهما.

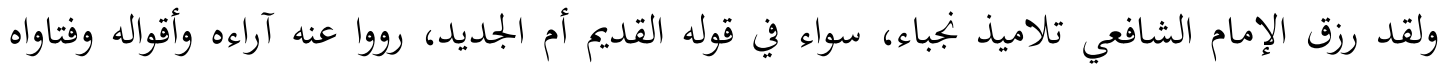

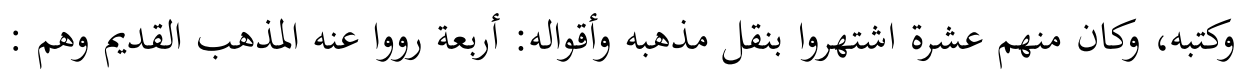

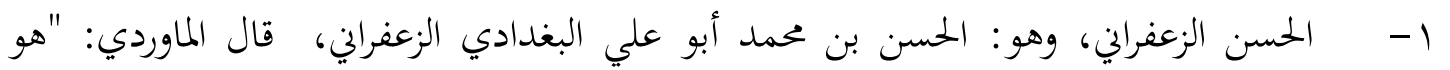
أثبت رواة القديم". توفي في رمضان سنة ستين ومائتين.

هذا البحث منشور في مجلة جامعة الملك عبد العزيز العدد الثاني - جمادى الثانية موبا هـ. وقارن هذا التقسيم مع ما ذكره

$$
\begin{aligned}
& \text { الحبيشي في المدخل إلى مذهب الإمام الشافعي ص. } 71 \text {. } \\
& \text { ' انظر أيضا: المدخل إلى مذهب الشافعي للقواسمي ص. . جr. } \\
& \text { محمد إحسان,المذهب الشافعي في إندونيسيا؛ تأريخه و آثاره }
\end{aligned}
$$


البصيرة: مجلة الاراسات الإسلامية

AL-BASHIRAH: JOURNAL OF ISLAMIC STUIDES

Vol. 1 No. 1(2020): 61-80

Website: https://journal.stiba.ac.id

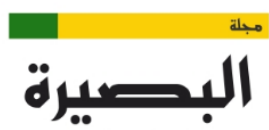

مجلة الصراعات الإعلامية

AL-BASHIRAH

Y- - ب الإمام أحمد بن حنبل وهو: أبو عبد الله أحمد بن محمد بن حنبل بن هلال الشيباني.

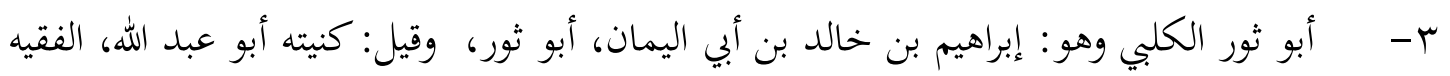

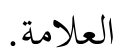

ع - أبو علي الكرابيسي، وهو: الحسين بن علي بن يزيد أبو علي البغدادي الكرابيسي، أخذ الفقه

$$
\begin{aligned}
& \text { عن الشافعي، وكان أولاً على مذهب أهل الرأي. }
\end{aligned}
$$

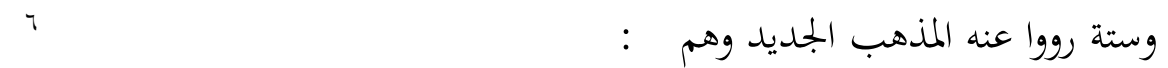

1 - أبو يعقوب البويطي وهو: يوسف بن يجيى القرشي أبو يعقوب البويطي المصري الفقيه، أحد

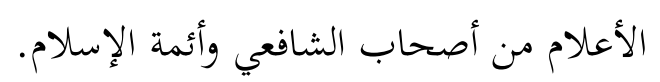

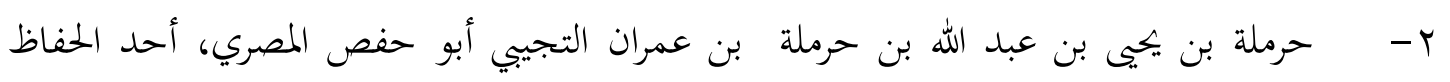

$$
\text { المشاهير من أصحاب الشافعي وكبار رواة مذهبه الجديد. }
$$

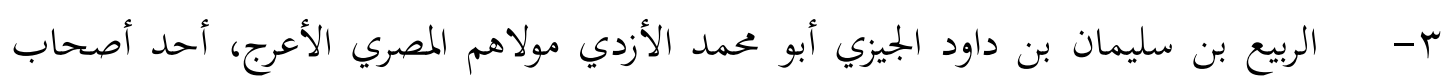

$$
\text { الشافعي والرواة عنه. }
$$

ع - إسماعيل بن يجيى بن إسماعيل بن عمرو بن إسحاق أبو إبراهيم المزيخ المصري الفقيه الإمام

$$
\text { صاحب التصانيف. }
$$

ه- - يونس بن عبد الأعلى بن ميسرة بن حفص بن حيان الصدفي أبو موسى المصري، أحد

$$
\text { أصحاب الشافعي وأئمة الحديث. }
$$

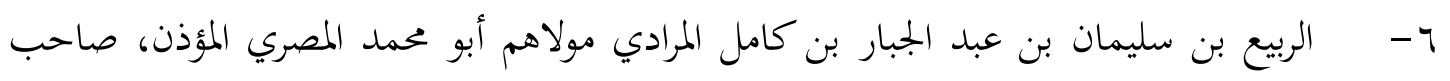

$$
\text { الشافعي وخادمه وراوية كتبه الجلديدة. }
$$

الطور الثالث: طور تحرير المذهب و تنقيحه:

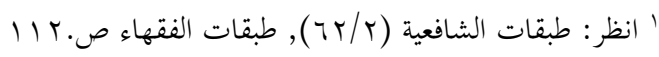

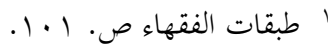

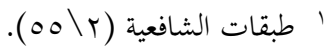

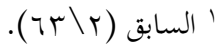

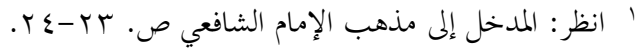

$$
\begin{aligned}
& \text { محمد إحسان, المذهب الشافعي في إندونيسيا؛ تأريخه و آثاره }
\end{aligned}
$$


البصيرة: مجلة الاراسات الإسلامية

AL-BASHIRAH: JOURNAL OF ISLAMIC STUIDES

Vol. 1 No. 1(2020): 61-80

Website: https://journal.stiba.ac.id

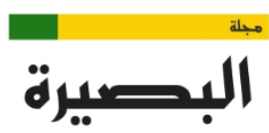

مجلة الصراهات الإهلامية

AL-BASHIRAH

هذا الطور يبدأ من أواخر القرن السادس الهجري بظهور جهد الإمام أبي القاسم الرافعي و من بعده

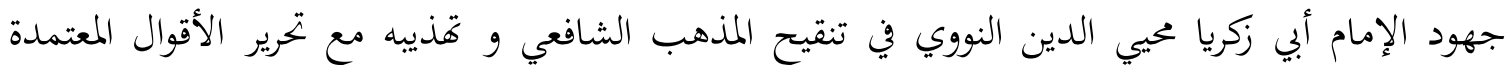
فيها. وقد قاما كرمهما الله- بمراجعة مصنفات الشافعية قبلهما. فلا يستغرب إن بقيت آراءهما وكتبهما مدار اعتماد الشافعية من بعدها حتى أواخر القرن التايع الهجري. الطور الرابع: طور الاستقرار: أما هذا الطور فإنه يبدأ من أواخر القرن التاسع الهجري من خلال جهود كل من الشيخ زكريا الأنصاري و الشهاب الرملي في خدمتهما للمذهب الشافعي حتى بلغت هذه الخدمة ذروقا على يد ابن حجر الهيتمي تم على يد شمس الدين الرملي من بعلده. فقد قام بتنقيح المذهب مرة أخرى و مراجعة مصنفاته.

$\wedge$

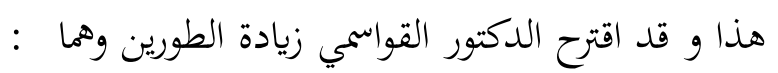

الطور الخامس: خدمة مصنفات التنقيحين الأول و الثاني للمذهب, وهو طور يمتد هذا من سنة وفاة شثم

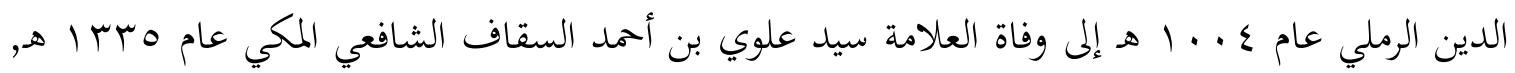
ثم الطور السادس: انخسار التمذهب بالمذهب الشافعي و تطور الدراسات الفقهية المعاصرة, ويمتد هذا الطور من عام Oبrا أهـ إلى اليوم.

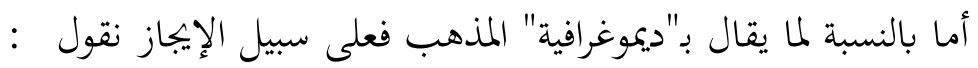

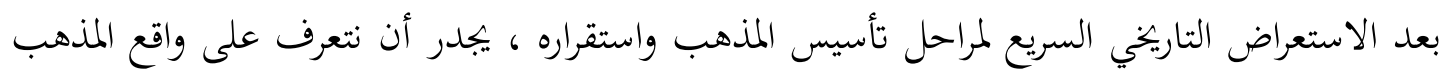
الشافعي حاليا من حيث الأماكن التي ينتشر فيها مُتِّبعوه في العالم الإسلامي والمجتمعات التي تتبناه مذهبا.

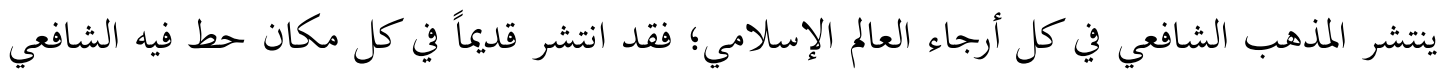

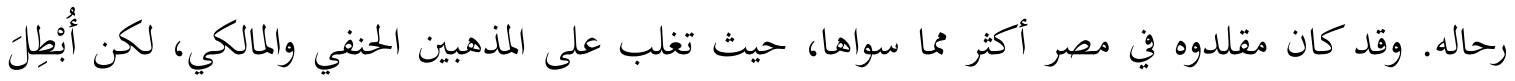

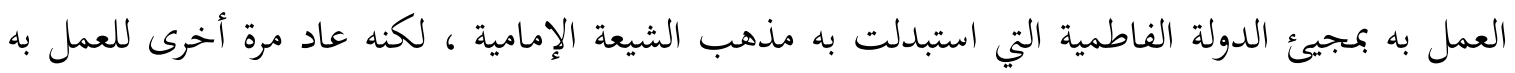

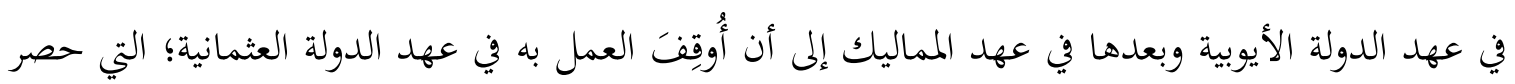

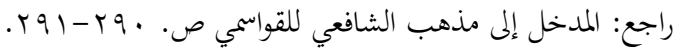

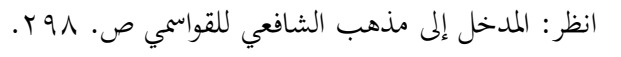

استفدت هذا البيان من مقالة تنشر في منتدى الملتقى الفقهي بعنوان: ديموغرافيا المذهب (أماكن الانتشار و المجتمعات 
البصيرة: مجلة الدراسات الإسلامية

AL-BASHIRAH: JOURNAL OF ISLAMIC STUIDES

Vol. 1 No. 1(2020): 61-80

Website: https://journal.stiba.ac.id

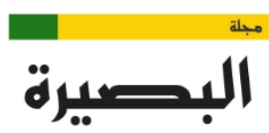

مجلة الصراهات الإهلامية

AL-BASHIRAH

حكامها القضاء في المذهب الحنفي لأنه مذهبهم. وإذا كان المذهب الشافعي قد فقد مكانته الرسمية في مصر، إلا أنه قد بقيت منزلنه لدى الشعب المصري، فإنه هو والمذهب المالكي قد تغلغلا في النفوس؛ لذا

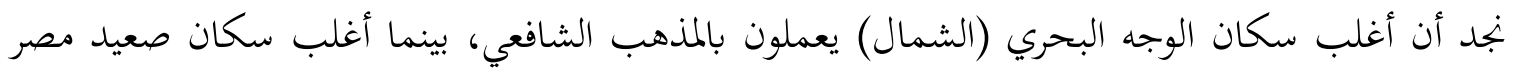
(الجنوب) يعملون بمقتضى الفقه المالكي. أما في بلاد الشام، فقد حل المذهب الشافعي محل مذهب الأوزاعي بتولي أبي زرعة الشافعي قضاء

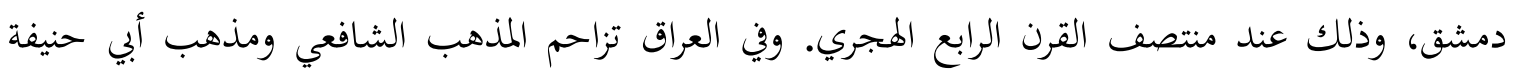
لمكانة الأخير عند الخلفاء والحكام. وقد كان للمذهب الشافعي مكانة عالية لوجود تلاميذ الشافعي الأولين، ولججرة كثير من أصحاب الشافعي وعلماء الشافعية إلى العراق، فكانت لهم منزلة لدى الخلفاء وإن كان

القضاء عند الحنفية.

وفي بلاد خراسان وسجستان وما وراء النهر، انتشر المذهب الشافعي، وقد ساعد على انتشاره علماء

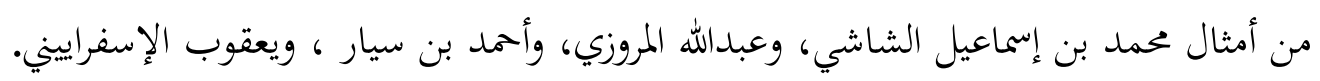

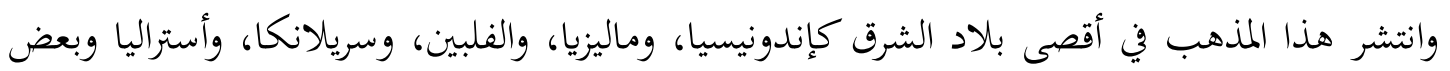

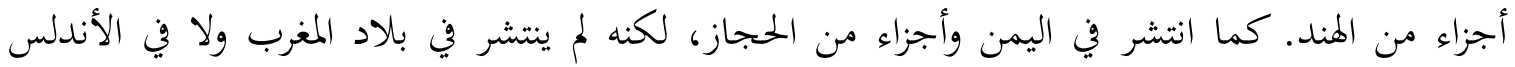
لتمكن المذهب المالكي وغلبته فيها.

وسنبين نوعا من التفصيل حول دخول المذهب الشافعي في إندونيسيا في المطلب القادم إن شاء الله.

المبحث الثاين: تاريخ المذهب الشافعي في إندونيسيا

عندما نريد الحديث حول تاريخ المذهب الشافعي في جنوب شرقي إنسيا أسيا و في إندونيسيا على سبيل

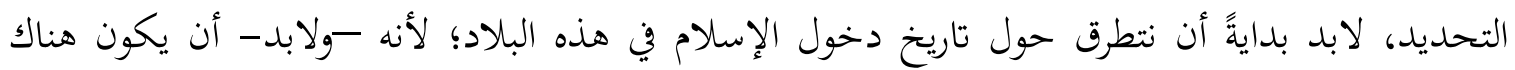
علاقة وثيقة بين الأمرين. فالمذهب الشافعي مذهب فقهي إسلامي. فهو جزء عملي من الإسلام يعمل به إله

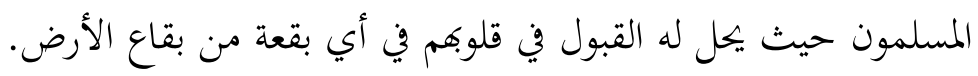

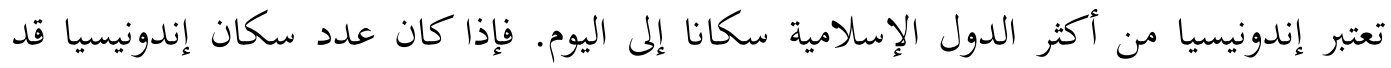

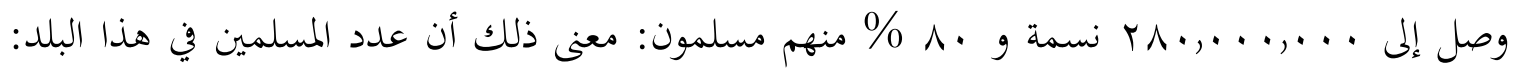

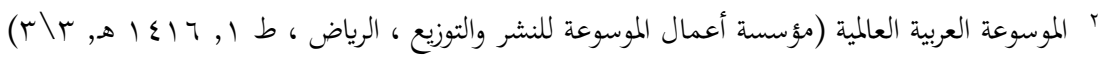

$$
\begin{aligned}
& \text { محمد إحسان, المذهب الشافعي في إندونيسيا؛ تأريخه و آثاره }
\end{aligned}
$$


البصيرة: مجلة الدراسات الإسلامية

AL-BASHIRAH: JOURNAL OF ISLAMIC STUIDES

Vol. 1 No. 1(2020): 61-80

Website: https://journal.stiba.ac.id

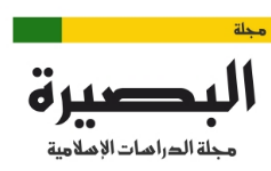

AL-BASHIRAH

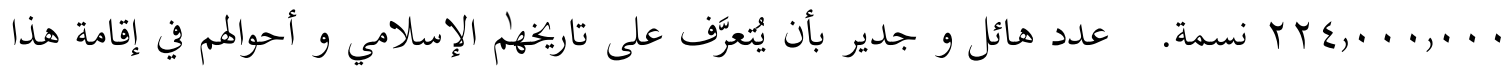

$$
\text { الدين العظيم و تطبيقه في حياقم اليومية. }
$$

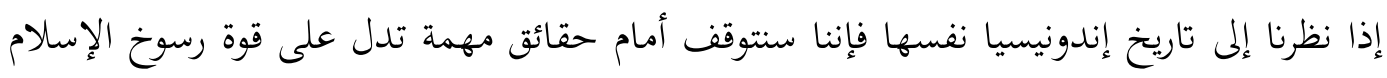

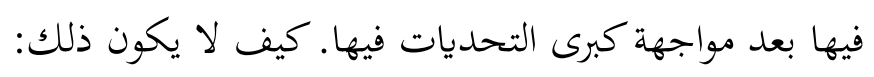

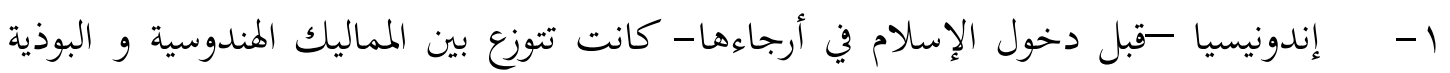

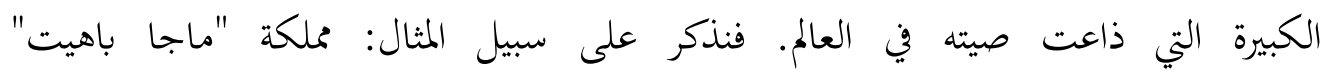

(Majapahit)

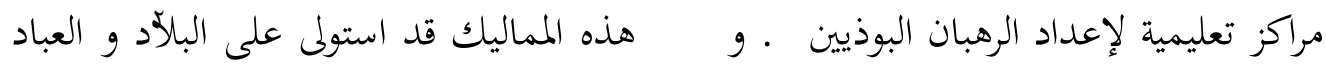

قرنا بعد قرن.

r - ولا ننسى أيضا بأن إندونيسيا قد وقعت تحت أسير الاستعمارت المتتابعة من البرتغال ثم هولندا

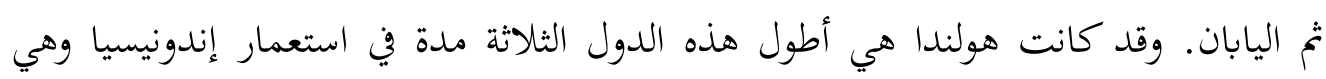
• هr سنة! ومن المعلوم أن استعمار هولندا كان يصحبه أيضا البعثات التنصيرية المتعاقبة.

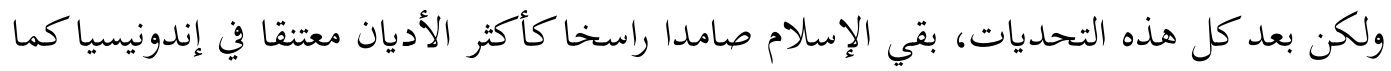

أما بنسبة تاريخ دخول الإسلام في إندونيسيا فهناك -على الأقل - ثلاث نظريات قدمها الباحثون في تحليل ذلك: النظرية الأولى: نظرية قوجرات و المليبار (وهما منطقتان في جزر الهند):

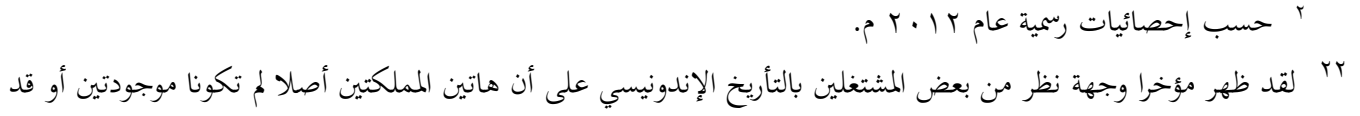

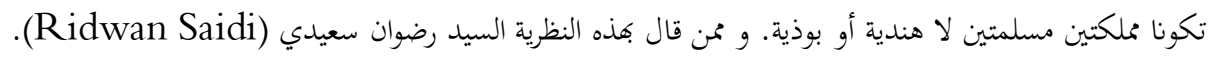
محمد إحسان, المذهب الشافعي في إندونيسيا؛ تأريخه و آثاره 
البصيرة: مجلة الاراسات الإسلامية

AL-BASHIRAH: JOURNAL OF ISLAMIC STUIDES

Vol. 1 No. 1(2020): 61-80

Website: https://journal.stiba.ac.id

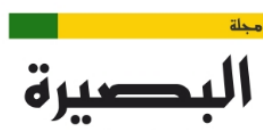

مجلة الدراهات الإهلامية

AL-BASHIRAH

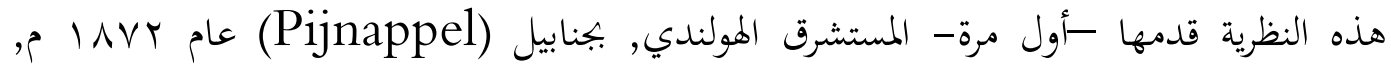

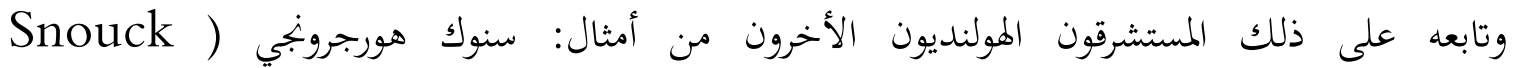
(Morrison) و موريسون (Moronje) تقول هذه النظرية بأن أول دخول الإسلام إلى الجزر الإندونيسية كان بواسطة تجار العرب الشوافع

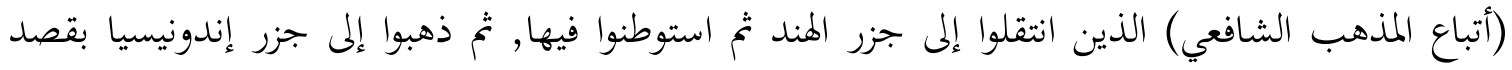

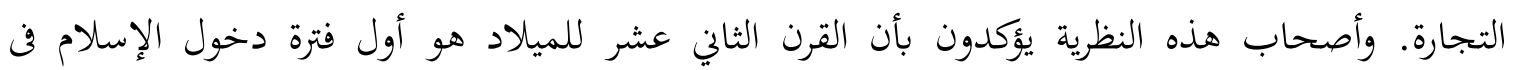
إندونيسيا. وكان من مستنداقم هو وجود الحجر المنقوش الذي يوضع عادة على القبر للدلالة على صاحب فرتب

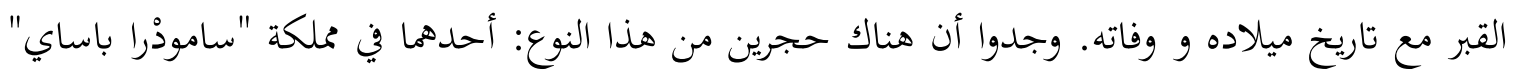
(Samudra Pasai)

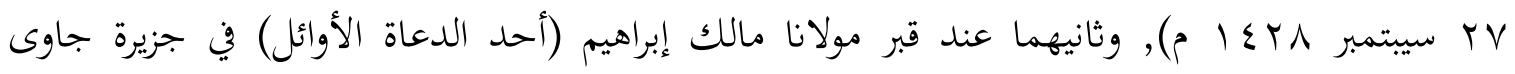

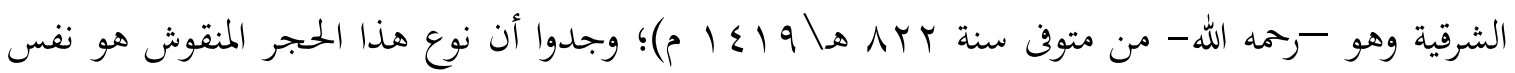
النوع الذي وجد و صنع في قوجارات.

ولكن جاء أصحاب النظرية الثانية (نظرية فاطمي) وردوا على أصحاب النظرية الأولى بأن الحجر

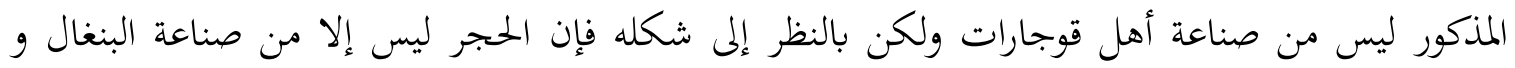

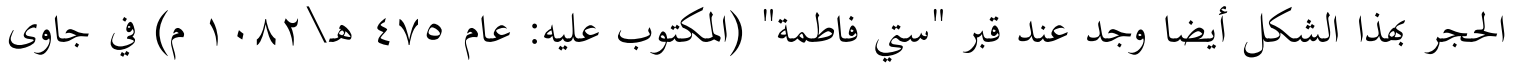

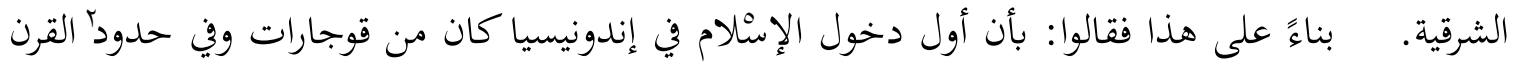
التاسع الميلادي.

ولكن استُشْكِل عليها بأن مسلمي إندونيسيا كانوا على المذهب الشافعي و مسلمو البنغال كانوا على المذهب الحنفي. ففي نظري -ووالله أعلم - هذه النظرية من أضعف النظريات حجةً و مستندةً.

rr Azyumardi Azra, Jaringan Ulama Timur Tengah dan Kepulauan Nusantara Abad XVII dan Abad XVIII (Jakarta: Prenada Media, 2003), p. 2.

Ázyumardi Azra, op.cit., p. 2-3

${ }^{r}$ SQ. Fatimi, Islam Comes to Malaysia (Singapore: Malaysian Sociological Institute, 1963), p. 31-32. 
البصيرة: مجلة الاراسات الإسلامية

AL-BASHIRAH: JOURNAL OF ISLAMIC STUIDES

Vol. 1 No. 1(2020): 61-80

Website: https://journal.stiba.ac.id

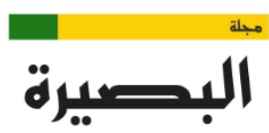

مجلة الصراهات الإهلامية

AL-BASHIRAH

أما النظرية الثالثة في هذه المسألة فإفا تقول: بأن الإسلام دخل في الجزر الإندونيسية عن طريق مسلمي الجزيرة العربية مباشرة, وبالضبط بواسطة أهل حضرموت. هذه النظرية قدمها أيضا بعض

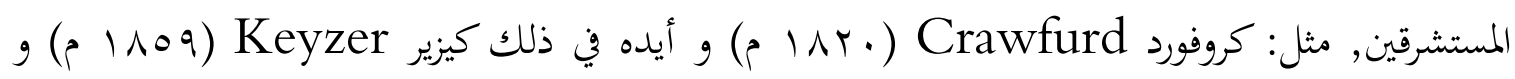

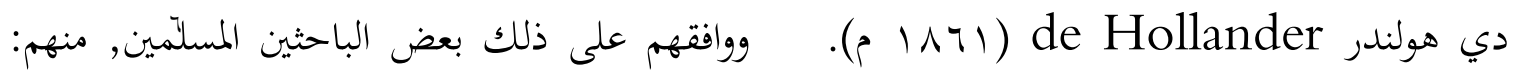
الدكتور الحاج عبد الملك كريم و نقويب العطاس. ومن مستنداقم في هذا:

ا - وجود الوثائق التي تدل على وجود الزيارات و العلاقات التجارية بين بحار العرب مع أهل إندونيسيا منذ القرن السابع الميلادي (أي في القرن الأول الهجري!) .من ذلك - مكما ذكره تومس أرنولد Thomas W. Arnold (T/ I I)- وجود حي يسكنه العرب على $\wedge$ الساحل الغربي من جزيرة سومطرة عام ع ؟ م. م.

r- وجود التشابه في المذهب الفقهي بين حضرموت و إندونيسيا وهو المذهب الشافعي.

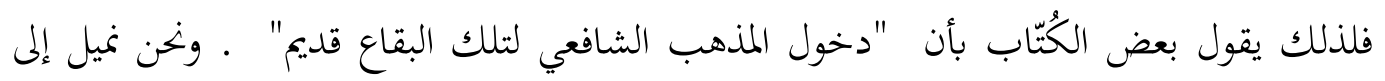
هذه النظرية الثالثة. ولعل محا يؤكد ذلك ما ذكره ابن بطوطة (ت VVq هـ) في رحلته: "ذكر سُطلطان الجَاوَةٍ ، وهو السلطان الملك الظاهر من فضلاء الملوك وكرمائهم، شافعيُّ المذهب ، حجبُّ في الفقهاء يحضرون مجلسه للقراءة والمذاكرة وهو كثير الجهاد والغزو ومتواضع يأتي إلى صلاة الجمعة ماشياً على قدميه ، وأهل بلاده شافعية محبُون في الجهاد يخرجون معه تطوعاً ، وهم غالبون على من يليهم

「̌ransformasi Hukum Islam Menuju Hukum Positif di Indonesia, p. 2.

‘A. Hasjmi, Sejarah Masuk dan Berkembangnya Islam di Indonesia (Bandung: alMa'arif, 1989), p. 7.

T.W. Arnold, The Preaching of Islam: A History of Propagation of the Muslim Faith (London: Constable, 1913), p. 364-365.

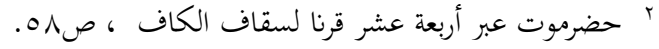

$$
\begin{aligned}
& \text { ·r اسم لأهم الجزر الإندونيسية الخمسة حيث العاصمة في يومنا هذا. }
\end{aligned}
$$

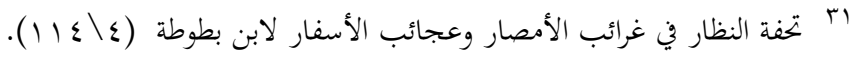

$$
\begin{aligned}
& \text { محمد إحسان,المذهب الشافعي في إندونيسيا؛ تأريخه و آثاره }
\end{aligned}
$$




\section{البصيرة: مجلة الدراسات الإسلامية \\ AL-BASHIRAH: JOURNAL OF ISLAMIC STUIDES \\ Vol. 1 No. 1(2020): 61-80}

Website: https://journal.stiba.ac.id

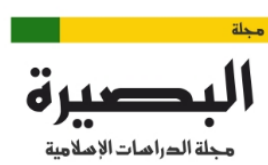

AL-BASHIRAH

JOURNAL OF ISLAMIC STUDIES

ومنذ زمن قديم يرحل أعداد كبيرة من الطلبة الإندنوسيين لطلب الفقه الشافعي خصوصا إلى مكة وحضرموت ومصر. ويعد هؤلاء من أهم المجتمعات التي تتبنى المذهب الشافعي نظرا لكثرة عددهم وعدم مدمدين وجود مذهب آخر ينافس المذهب الشافعي في تلك البقاع حينذاك.

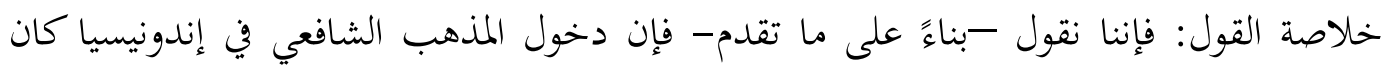
مصاحباً مع دخول الإسلام في هذه البقاع، حتى و إن قلنا و أخذنا بالنظرية الأولى في المسألة. والله تعالى أعلم.

وقد ذكر الباحث عبد الرحمن حاج عبد الله بأن من أوائل الكتب الشافعية التي وصلت و دخلت

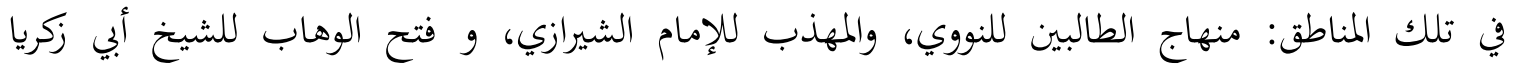
الأنصاري ثم فتح المعين لزين الدين الماليباري.

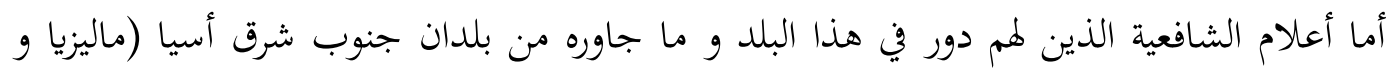

$$
\text { تايلاند و بروناي و الفلبين) فنذكر منهم كالتالي: }
$$

r- - الشيخ تاج الدين الإصفهاني. وقد ذكر بعض الباحثين بأن الملك الظاهر -الذي ذكره ابن

بطوطة في رحلته- قد التقى بهما في مملكته.

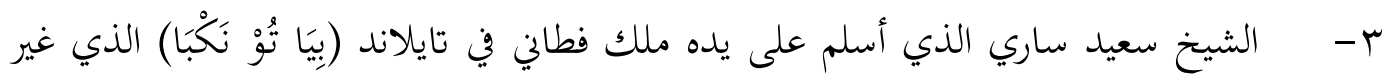

$$
\begin{aligned}
& \text { اسمه لاحقا ب"سلطان الإسلام ظل الله في العالم". } \\
& \text { ع - - الشيخ محمد نووي الجاوي (ت ما ابرا هـ) }
\end{aligned}
$$

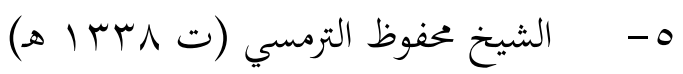

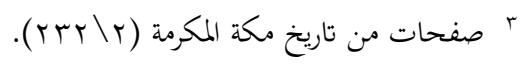

${ }^{r}$ Abdurrahman Haji Abdullah: Pemikiran Umat Islam di Nusantara (Kuala Lumpur: Dewan Bahasa \& Pustaka, 1990), p. 120-121, Mahmud Yunus: Sejarah Islam di Minangkabau (Jakarta: al-Hidayah, 1971), p. 10.

A.Teaw \& D.K. Wyatt: Hikayat Patani (The Hague: Martinus Nijhoff, 1970), p. 71-75, Mahmood Zuhdi Haji Abd. Majid: Mazhab Syafi'I di Malaysia, Sejarah, Realiti dan Prospek Masa Depan, Jurnal Fiqh: no. 4 (2007), p. 3-4.

$$
\text { محمد إحسان, المذهب الشافعي في إندونيسيا؛ تأريخه و آثاره }
$$


البصيرة: مجلة الاراسات الإسلامية

AL-BASHIRAH: JOURNAL OF ISLAMIC STUIDES

Vol. 1 No. 1(2020): 61-80

Website: https://journal.stiba.ac.id

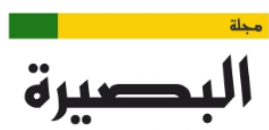

مجلة الصراهات الإهلامية

AL-BASHIRAH

7- - الشيخ نور الدين الشافعي الرانيري. وقد ألف كتابا في الفقه الشافعي بعنوان: "الصراط

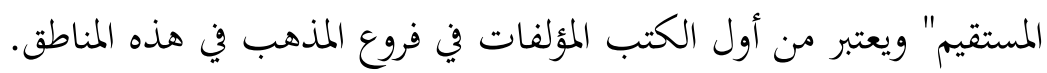

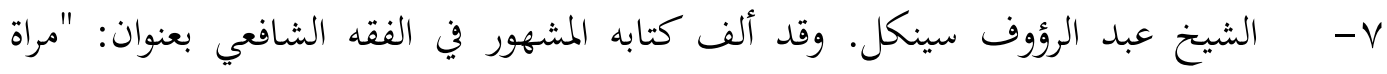

الطلاب"، وهو أشثل من كتاب الرانيري.

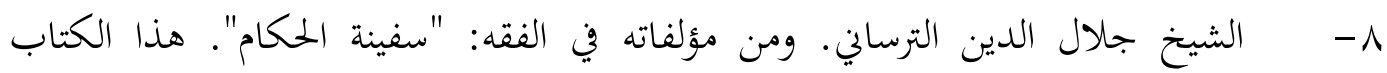

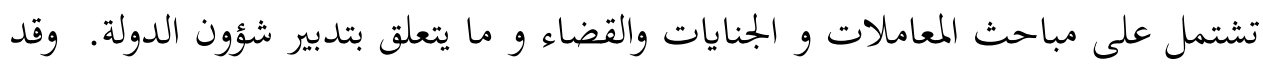

كانوا على منصب "شيخ الإسلام" في منطقة أبتيه (سومطرة) في ذاك الوقت.

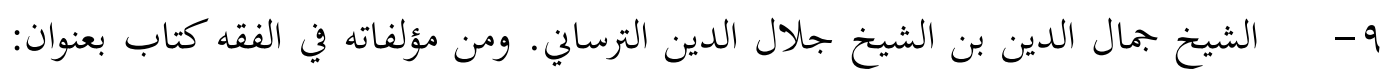

$$
\text { "هداية العوام" في الفروع و "فرائض القران" في الفرائض. لئ. }
$$

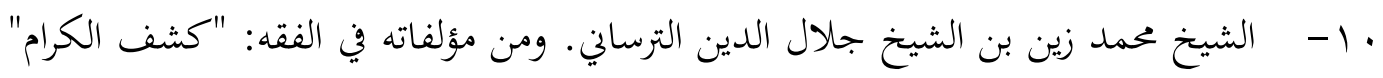

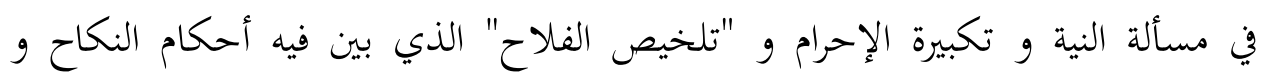

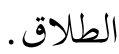

11 - الشيخ محمد أرشد البَنْجرِي. بعد أن جلس في مكة .ب سنة لطلب العلم، رجع إلى مسقط رأسه في مملكة بَنْجر في جزيرة كالمنتان حيث عين مفتيا في عهد السلطان تحميد

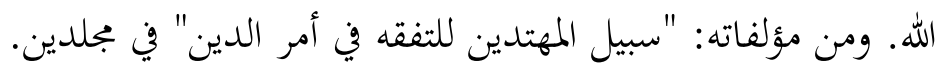

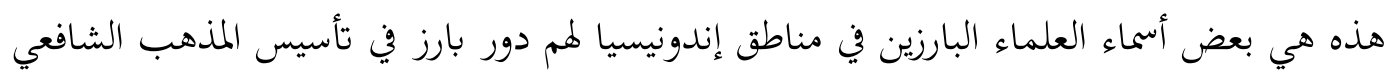
و نشره فيها. وفي المبحث القادم سنتعرف على مدى تأثيرهم في تعليم الفقه و في القوانين.

المبحث الثالث: آثار المذهب الثافعي في إندونيسيا

المطلب الأول: آثار المذهب الشافعي في تعليم الفقه في إندونيسيا

مملكة سامودرا باسي (Samudera Pasai) هي أولى مملكة إسلامية وجدت على مدار تاريخ

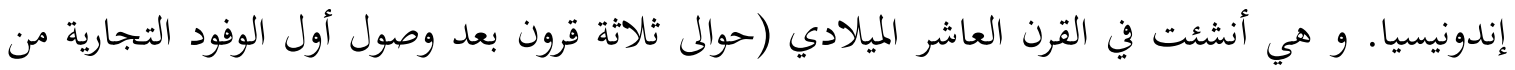

Mahmood Zuhdi Haji Abd. Majid: op.cit., p. 7-8.

"Mahmood Zuhdi Haji Abd. Majid: op.cit., p. 8-9.

r'Zalila Sharif \& Jamilah Haji Ahmad: Sastera Melayu Tradisional (Kuala Lumpur: Dewan Bahasa dan Pustaka, 1993), p. 399.

محمد إحسان, المذهب الشافعي في إندونيسي؛ تأريخه و آثاره 
البصيرة: مجلة الدراسات الإسلامية

AL-BASHIRAH: JOURNAL OF ISLAMIC STUIDES

Vol. 1 No. 1(2020): 61-80

Website: https://journal.stiba.ac.id

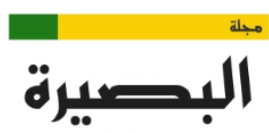

مجلة الدراهات الإهلامية

AL-BASHIRAH

الجزيرة العربية إلى تلك البقاع كما مر معنا). وقد ذكر ابن بطوطة -كما مر أيضا- أنه التقى مع أحد ملوك هذه المملكة: الملك الظاهر. واستفدنا أيضا من بيان ابن بطوطة عدة أمور وهي: 1 - إلمواد الدراسية في الفقه كانت على المذهب الشافعي.

r - طريقة التعليم و التدريس كانت على طريقة الحلقات و المجالس في المساجد.

$$
\text { r- التكاليف التعليمية كانت على دعم كامل من الحاكم. }
$$

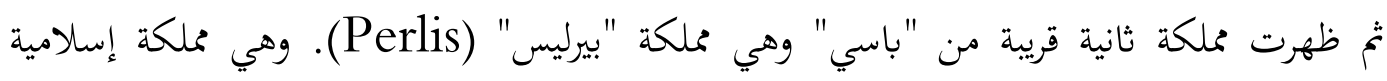

أيضا، بل كان حاكمها السادس: السلطان مخدوم علاء الدين عالما من العلماء و أنشأ "جامعة إسلامية" وتهية

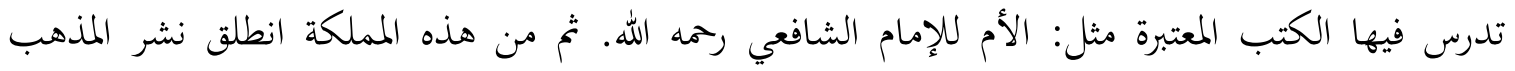

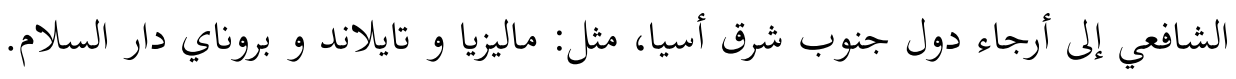
وبعد ذلك، تتابعت المماليك الإسلامية على نفس النهج و الشاكلة. كثرت المعاهد و المدارس في مئي أرجاء تلك المماليك و المنهج التدريسي لا يختلف كثيرا مع ما مر من الاعتماد على الفقه الشافعي.

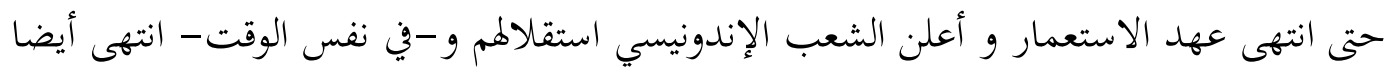
عهد المماليك حيث اتفقت تلك المماليك على تسليم سلطتهم إلى الحكومة الإندونيسية الجديدة التي يتبنى

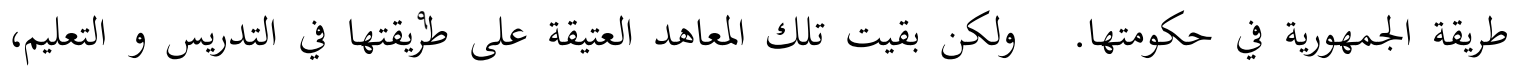
خاصة فيما يتعلق بتعليم الفقه على المذهب الشافعي. في عهد الاستقلال الإندونيسي، ظهرت جمعيات إسلامية تعتني بالمذهب الشافعي فقها من خلال

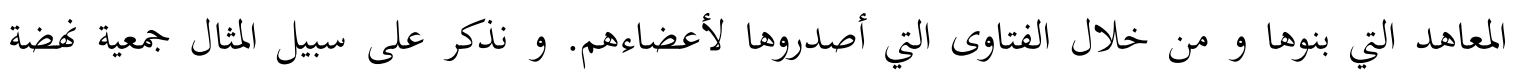

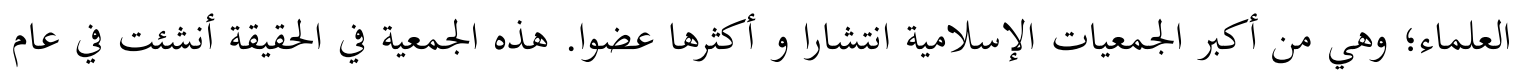

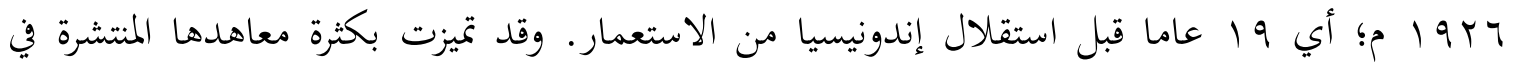
جزيرة جاوى على سبييل الخصوص.

'Departemen Agama: Sejarah Islam Indonesia (Jakarta: Departemen Agama, 1980), p. 16.

'Departemen Pendidikan \& Kebudayaan: 30 Tahun Indonesia Merdeka (Jakarta: Van Hoeve, 1985), p. 34.

$$
\text { No } \quad \text { Vo }
$$


البصيرة: مجلة الاراسات الإسلامية

AL-BASHIRAH: JOURNAL OF ISLAMIC STUIDES

Vol. 1 No. 1(2020): 61-80

Website: https://journal.stiba.ac.id

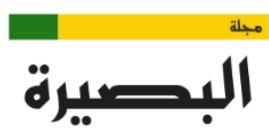

مجلة الصراهات الإهلامية

AL-BASHIRAH

وإذا نظرنا إلى ميثاق الجمعية حين أنشئت فإنه ينص على أن الجمعية تتمذهب بالمذهب الشافعي,

$$
\begin{aligned}
& \text { و إذا وجد الخلاف في المذهب فسيتم اختيار القول على الترتيب التالي : } \\
& \text { 1- القول الذي اتفق عليه الشيخان ( النووي و الرافعي). }
\end{aligned}
$$

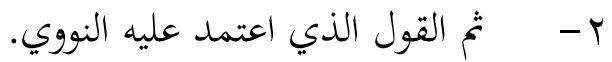

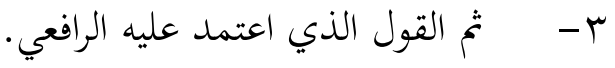

$$
\begin{aligned}
& \text { ع - تم القول الذي أيده أكثر العلماء (الثافعية؟). }
\end{aligned}
$$

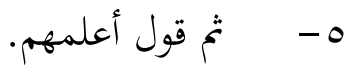

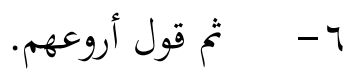

هكذا، ومع مرور الأيام -ـلأسف - بدأ هذا النوع من التفقه -أعني على طريقة التمذهب بالمذهب

الشافعي - تتلاشى و تنحصر فقط في بعض المعاهد القديمة فقط.

المطلب الثاني: آثار المذهب الشافعي في القوانين الإندونيسية

عندما احتل الإسلام موطنا راسخا في قلوب المجتمع الإندونيسي قبل نشأة المماليك الإسلامية، كان

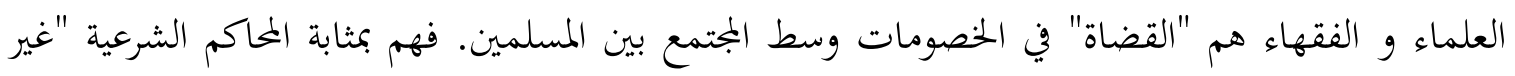

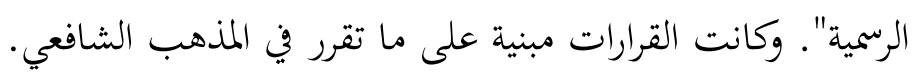

واستمرت هذا النهج حتى بعد قيام المماليك الإسلامية في إندونيسيا، مثل: مملكة سامودرا باساي،

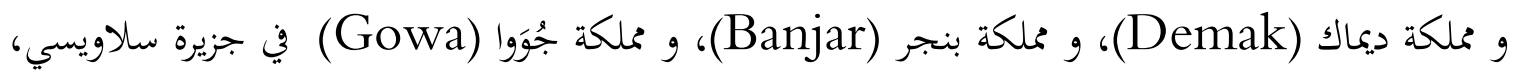
و مملكة مالوكو (Maluku) في جزيرة الملوك. وصارت كتب الشافعية هي المعتبرة في القضاء.

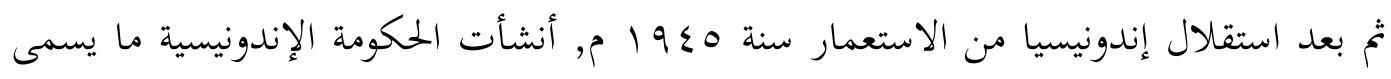

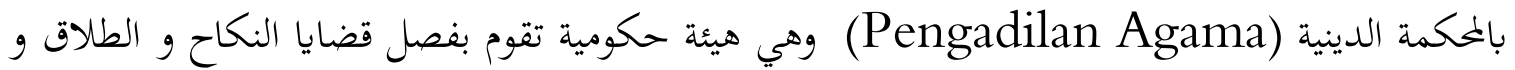

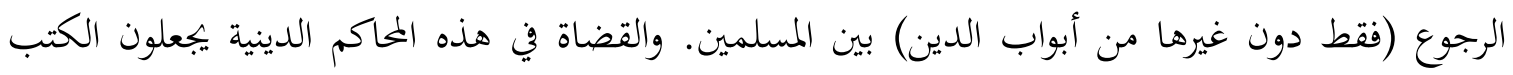
الشافعية كمصدر إثبات القرار.

'Lajnah Bahtsul Masa'il NU: Metode Pengambilan Keputusan (Surabaya: NU Press, 1990), p. 56.

'Abdullah Shaleh: Madzhab Syafi'i di Indonesia (Jakarta: N.N.), p. 12.

$$
\text { محمد إحسان, المذهب الشافعي في إندونيسيا؛ تأريخه و آثاره }
$$


البصيرة: مجلة الدراسات الإسلامية

AL-BASHIRAH: JOURNAL OF ISLAMIC STUIDES

Vol. 1 No. 1(2020): 61-80

Website: https://journal.stiba.ac.id

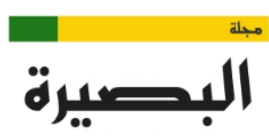

مجلة الصراهات الإصلامية

AL-BASHIRAH

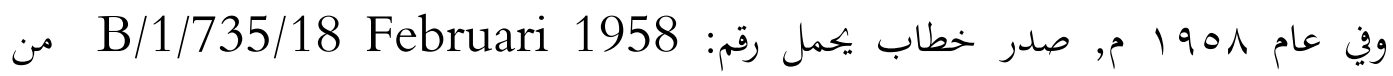

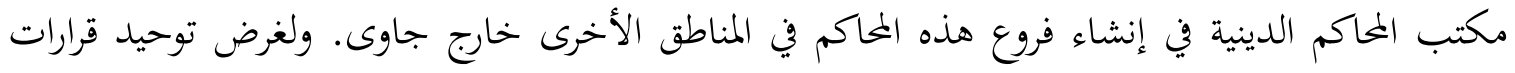
الحكم، بيَّن الحطاب نفسه بأن على القضاة في المناطق الاعتماد على الكتب التانية التالية:

$$
\begin{aligned}
& \text { - }
\end{aligned}
$$

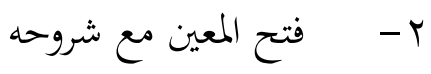

$$
\begin{aligned}
& \text { r- حاشية الشرقاوي على التحرير } \\
& \text { ع - فتح الوهاب مع شرحه } \\
& \text { ه- - تغريب المشتاق } \\
& \text { 1- - ق قوانين الشريعة للسيد عثمان يهيى }
\end{aligned}
$$

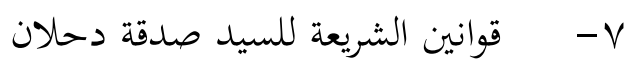

$$
\begin{aligned}
& \text { 1 - م- بغية المسترشدين }
\end{aligned}
$$

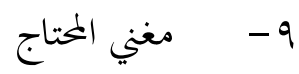

$$
\begin{aligned}
& \text { • }
\end{aligned}
$$

ثم في بداية الثمانينات الميلادية، ظهرت فكرة إصدار قوانين الحكم الإسلامي في قالب واحد. وهذه

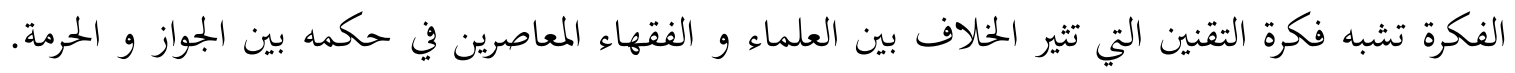

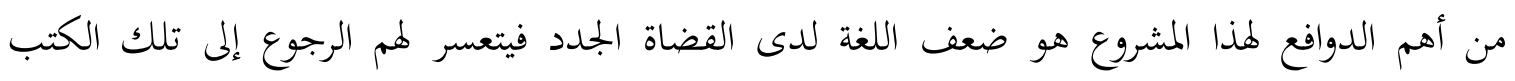

فصدر خطاب رسمي من قبل المكمة العظمى الإندونيسية (Mahkamah Agung ) و

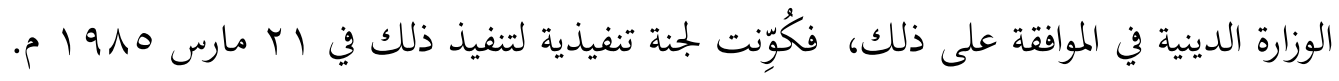

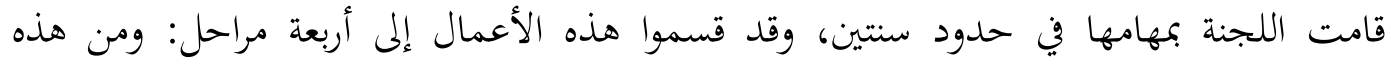

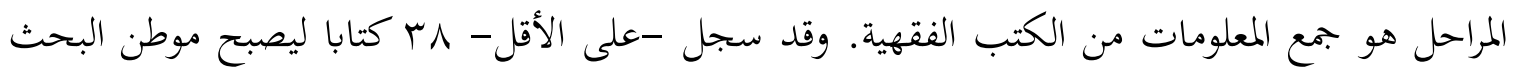


البصيرة: مجلة الدراسات الإسلامية

AL-BASHIRAH: JOURNAL OF ISLAMIC STUIDES

Vol. 1 No. 1(2020): 61-80

Website: https://journal.stiba.ac.id

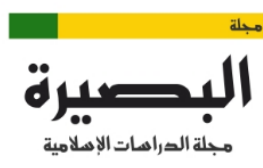

AL-BASHIRAH

في المشروع و ه \% من هذه الكتب: كتب فقهية شافعية. فوّض الأمر بعد ذلك إلى الجامعات الإسلامية الحكومية لإكمال مسيرة البحث و التنقيب في بطون تلك الكتب.

بعد أن أهت اللجنة المذكورة مشروعها في · ل يونيو 1991 م، صدر قرار رسمي من رئيس الجمهورية الإندونيسية رقم. 1 عام 1991 م في تنفيذ قوانين الحكم الإسلامي المذكور و نشرها في المحاكم الدينية. منذ ذلك الحين، صارت القوانين المذكورة مرجعا أساسيا في إصدار القرارت في قضايا الأحوال الشخصية (النكاح و الإرث) و الوقف و لم تعد بحاجة إلى الرجوع إلى تلك الكتب الفقهية -خاصة المذهب $\varepsilon$

ونلاحظ من خلال هذا العرض بأن الفقه الشافعي لا شك له أثر في القوانين الصادرة من قبل الحكومة الإندونيسية وإن كان مقتصرا على شؤوون الأحوال الشخصية فقط. و نلاحظ بأن الأحكام الشرعية -ـلأسف - لا تتجاوز شؤوون الزواج و الإرث و الوقف. هذا الأمر لا شك نقصٌ في توظيف الشريعة كمنهج حياةٍ للمسلمين في جميع شؤوغم.

الخاتمة:

وبعد عرض ما تقدم، تتجلى أهمية معرفة تاريخ المذاهب الفقهية و تطورها في العصر الحاضر؛ لأهما

ثروة عظيمة يتجلى من خلالما عظمة الشريعة الإسلامية ومدى أحقيتها لتكون هي الوحيدة منهاج حياة البشرية.

وفي هذا الحنتام، لا أجد إلا أن أتقدم ببعض النتائج التي توصلت إليها من خلال هذا البحث. وهذه هي أهم تلك النتائج:

1- - المذهب الشافعي مذهب فقهي عظيم، ويتميز بمميزات عظيمة منها: أنه بيجمع عصارة المذهبين: أهل الحديث و أهل الرأي، و أنه من رحمه المبارك قد قدم للأمة الإسلامية علماء نجباء قد سطروا التاريخ بآثارهم الجليلة.

¿Cik Hasan Basri: Hukum Islam dalam Tatanan Masyarakat Indonesia (Jakarta: Logos Wacana Ilmu, 1998), p. 134; Departemen Agama: Kompilasi Hukum Islam (Jakarta: Akademika Pressindo, 1992), p. 3. 
البصيرة: مجلة الاراسات الإسلامية

AL-BASHIRAH: JOURNAL OF ISLAMIC STUIDES

Vol. 1 No. 1(2020): 61-80

Website: https://journal.stiba.ac.id

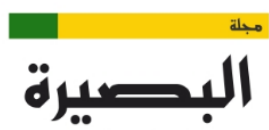

مجلة الصراهات الإصلامية

AL-BASHIRAH

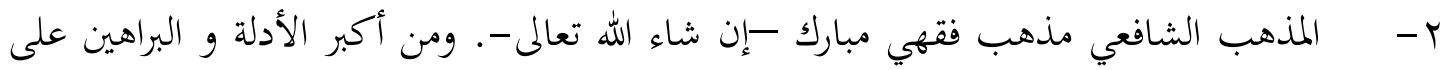

ذلك هو: بقاءه كمذهب فقهي معمول به عند المسلمين في أرجاء العالم الإسلامي إلى يومنا الكاديا

هذا.

r- دخول المذهب الشافعي في إندونيسيا كان مصاحباً مع دخول الإسلام فيها بواسطة تحار

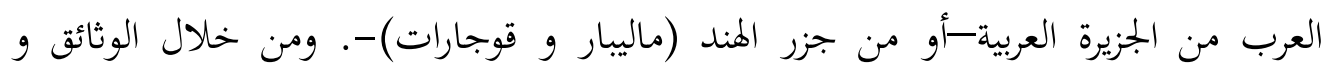

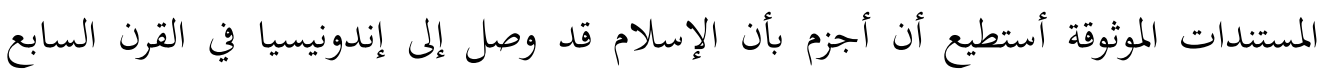

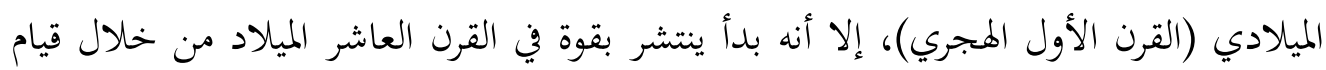

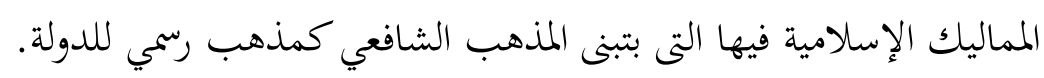

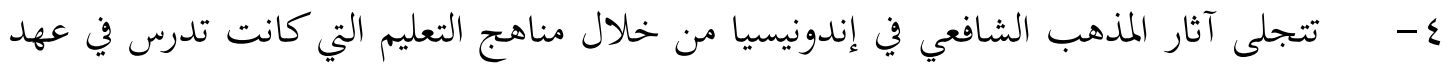

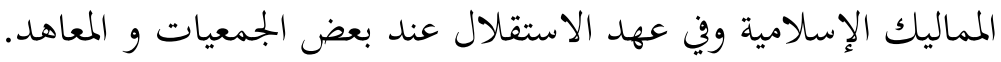

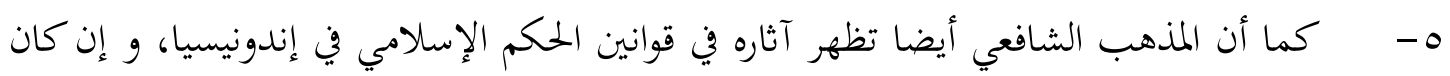

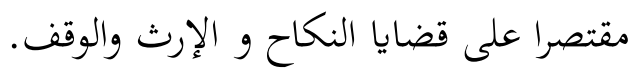
وفي المنتام، لا يفوتني أيضا أن أقدم بعض التوصيات الارت ولوقيف وهي:

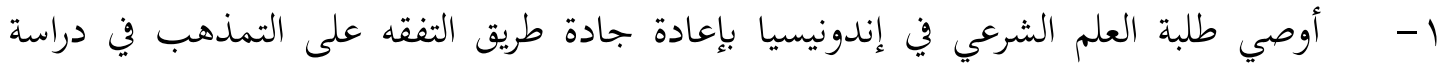

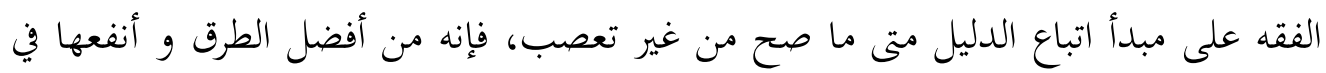
هذا السبيل. r- كما أوصي الباحثين أيضا بإبراز جهود العلماء الإندونيسين وذلك بالقيام بإخراج مؤلفاقم و تحقيقها حتى تخزج من ظلمة الأدراج إلى النور. هذا وأسأل الله تعالى أن ينفعني بهذا البحث المتواضع و أن يرزقني الإخلاص في القول والعمل.

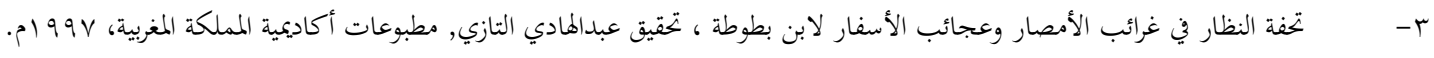




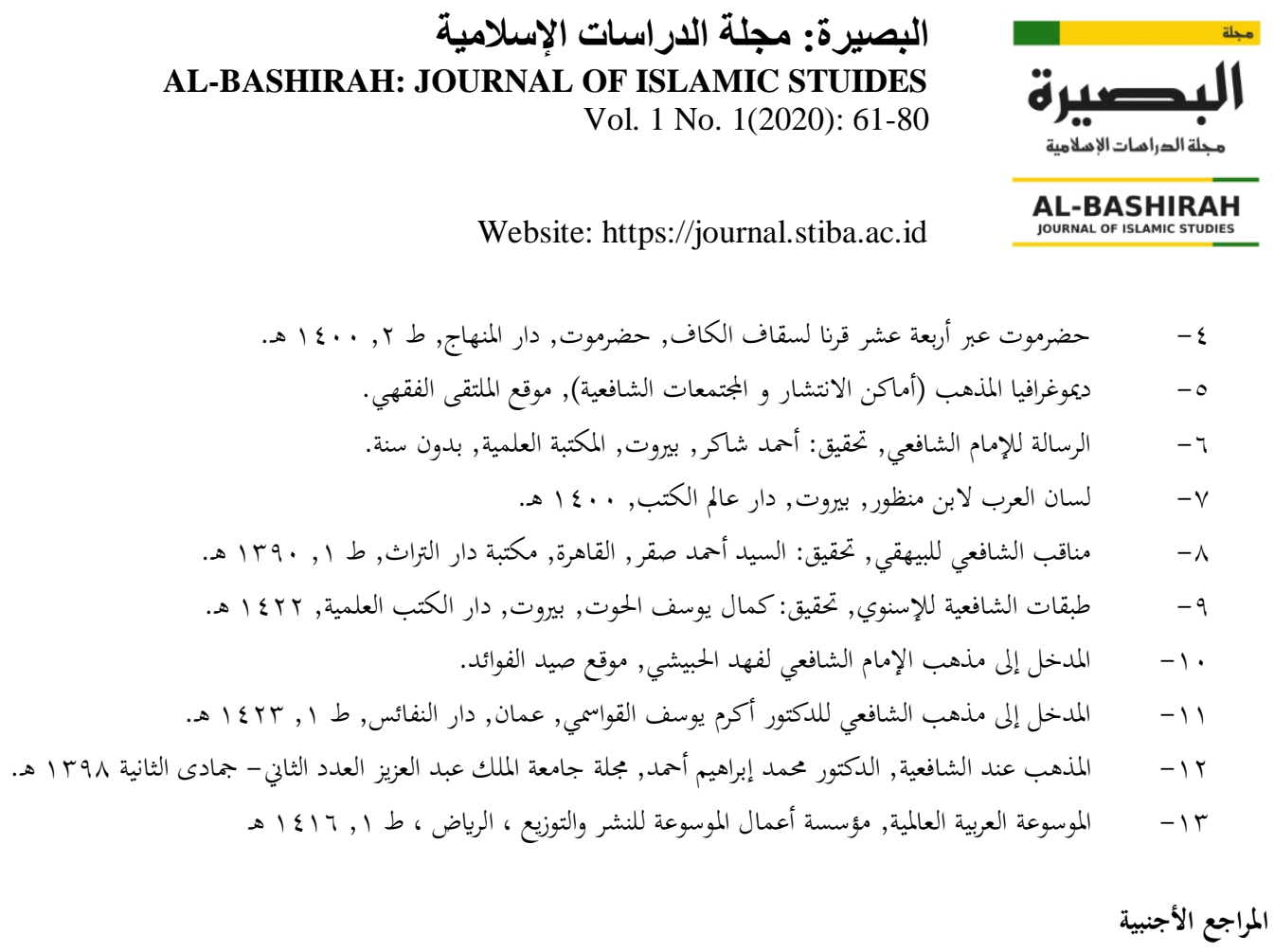

1. Abdullah Shaleh: Madzhab Syafi 'i di Indonesia (Jakarta: N.N.)

r. Abdurrahman Haji Abdullah: Pemikiran Umat Islam di Nusantara (Kuala Lumpur: Dewan Bahasa \& Pustaka, 1990)

r. A. Hasjmi, Sejarah Masuk dan Berkembangnya Islam di Indonesia (Bandung: al-Ma'arif, 1989)

£. A.Teaw \& D.K. Wyatt: Hikayat Patani (The Hague: Martinus Nijhoff, 1970)

- Azyumardi Azra, Jaringan Ulama Timur Tengah dan Kepulauan Nusantara Abad XVII dan Abad XVIII (Jakarta: Prenada Media, 2003)

7. Cik Hasan Basri: Hukum Islam dalam Tatanan Masyarakat Indonesia (Jakarta: Logos Wacana Ilmu, 1998)

v. Departemen Agama: Kompilasi Hukum Islam (Jakarta: Akademika Pressindo, 1992)

^. Departemen Agama: Sejarah Islam Indonesia (Jakarta: Departemen Agama, 1980)

9. Departemen Pendidikan \& Kebudayaan: 30 Tahun Indonesia Merdeka (Jakarta: Van Hoeve, 1985)

1. Lajnah Bahtsul Masa'il NU: Metode Pengambilan Keputusan (Surabaya: NU Press, 1990)

11. Mahmud Yunus: Sejarah Islam di Minangkabau (Jakarta: al-Hidayah, 1971)

Ir. Mahmood Zuhdi Haji Abd. Majid: Mazhab Syafi'I di Malaysia, Sejarah, Realiti dan Prospek Masa Depan, Jurnal Fiqh: no. 4 (2007)

1r. SQ. Fatimi, Islam Comes to Malaysia (Singapore: Malaysian Sociological Institute, 1963)

I. T.W. Arnold, The Preaching of Islam: A History of Propagation of the Muslim Faith (London: Constable, 1913)

. Zalila Sharif \& Jamilah Haji Ahmad: Sastera Melayu Tradisional (Kuala Lumpur: Dewan Bahasa dan Pustaka, 1993) 